\title{
DSG2 expression is low in colon cancer and correlates with poor survival
}

\author{
Tingting Yang ${ }^{1,2}$, Xuan Gu ${ }^{1,2}$, Lizhou Jia ${ }^{1,2}$, Jiaojiao Guo ${ }^{1,2}$, Qi Tang ${ }^{1}$, Jin Zhu ${ }^{1,4}$, Wei Zhao ${ }^{3^{*}}$ \\ and Zhenqing Feng ${ }^{1,2,5^{*}}$
}

\begin{abstract}
Background: Desmoglein2 (DSG2) is a transmembrane protein that helps regulate intercellular connections and contributes to desmosome assembly. Desmosome are associated with cell adhesion junctions, which play an important role in cancer progression specially cancer cell migration and invasion. However, DSG2 expression in colon cancer (CC) and its association with CC patients' overall survival (OS) are still unclear.
\end{abstract}

Methods: We collected 587 CC samples, 41 colitis tissues and 114 pericarcinomatous tissues, as well as corresponding clinicopathological data about the patients who contributed them. All samples were tested immunohistochemically in tissue microarrays. Kaplan-Meier method was used for calculating patient survival. Univariate and multivariate analyses was used for investigating DGS2 link with CC patient's clinicopathological factors. Bioinformatics analysis was also used in study.

Results: The results showed that DSG2 expression was lower in CC tissues than in pericarcinomatous tissues $(P<0.001)$. DSG2 expression was associated with differentiation $(P=0.033)$, lymph node metastasis $(P=0.045)$, distant metastasis $(P=0.006)$ and AJCC stage $(P<0.001)$. Univariate analysis indicated that poor OS in patients with CC was associated with low DSG2 expression $(P<0.001)$, tumor size $(P<0.001)$, lymph node metastasis $(P<0.001)$, distant metastasis $(P<0.001)$, AJCC stage $(P<0.001)$ and venous invasion $(P<0.001)$. In multivariate analysis, low DSG2 expression $(P<0.001)$, distant metastasis $(P<0.001)$, AJCC stage $(P=0.002)$, venous invasion $(P<0.001)$ were independent prognostic factors for CC patients. Bioinformatics analysis indicated that low DSG2 expression affects protein activation, regulates the P53-related pathway in CC, and activates the EGFR pathway.

Conclusions: The results suggest that low DSG2 expression is associated with poor survival for CC patients. DSG2 could be a prognostic biomarker for CC.

Keywords: DSG2, Colon cancer, Prognosis, Tissue microarray, Immunohistochemistry

\section{Background}

Among malignant tumors, colon cancer (CC) is the third most common in both morbidity and mortality, with roughly 1.2 million new cases and 600,000 deaths worldwide every year [1]. Age is the strongest risk factor for

\footnotetext{
*Correspondence: zhaowei_njmu@163.com; fengzhenqing@njmu.edu.cn

${ }^{1}$ Key Laboratory of Antibody Technique of National Health Commission,

Nanjing Medical University, Nanjing 211166, China

${ }^{3}$ Department of Pathology, Nanjing First Hospital, Nanjing Medical

University, Nanjing 210006, China

Full list of author information is available at the end of the article
}

CC; whereas its incidence rate is low in people younger than 50 years old, the number of Chinese patients with $\mathrm{CC}$ is expected to increase greatly in coming years as the median age of the Chinese population increases [2] Five-year survival rates for localized stage and regionally spread CC are $90.1 \%$ and $69.2 \%$, respectively. However, the 5 -year survival rate for distantly spread colon cancer is only $11.7 \%$ [3]. Early invasion or spread of CC indicates higher malignancy and poor prognosis. Surgery is the main treatment for both early- and late-stage CC, but tumors recur in $30 \%-50 \%$ of all cases, usually presenting 
as metastasis [4] Chemotherapy involves the use of antineoplastic agents that do not significantly distinguish between cancer and normal cells. Therefore, finding specific biomarkers for $\mathrm{CC}$ diagnosis and therapy is imperative $[5,6]$.

The desmoglein2 (DSG2) gene is located at chromosome 18q12.1. It encodes a single transmembrane protein. As a member of the classical cadherin family, DSG2 is calcium-dependent and assembles to make desmosomes. Ramani et al. found that shedding of soluble DSG2 was increased in pancreatic cancer, and that the loss of DSG2 may lead to cancer invasion [7]. Low DSG2 expression has been reported in aggressive prostate cancer [8], squamous lung cancer [9] and gastric cancer [10]. DSG2 can be used as a prognostic biomarker for cancer patients. Yang Liu et al. confirmed that DSG2 was decreased in KLF5 knockdown cells, and was related to intestinal barrier function. Dysfunction of intestinal barrier could lead to increasing intestinal permeability and intestinal inflammatory disease [11]. Patients with intestinal inflammatory diseases have higher risks of CC compared with the general population [12]. In cancer progress, inhibition of cell-cell adhesion is an indispensable first step in the metastatic process. However, few studies have investigated DSG2 expression and its function in CC.

To evaluate the role of DSG2 in CC prognosis and diagnosis, we assessed DSG2 expression in CC tissues and adjacent mucosa tissues by immunohistochemistry (IHC) staining in tissue microarrays (TMAs). The relationship between DSG2 expression and patients' overall survival (OS) and clinicopathological factors were calculated by univariate and multivariate analysis. Bioinformatics methods were used to study DSG2-related signaling pathway.

\section{Methods}

\section{Human tissue samples and homologous clinicopathological data}

We collected 587 CC tissues, 41 colitis tissues and 114 pericarcinomatous tissues (total of 742 samples) from Nanjing First Hospital, Nanjing Medical University, which were collected from patients treated between 2006 and 2012. All samples were formalin-fixed and paraffinembedded. Homologous clinicopathological data were also collected, including patients' sex, age, tumor location, histological type, differentiation grade, tumor size, lymph node metastasis, distant metastasis, AJCC stage, venous or perineural invasion, preoperative CEA and CA199 serum level and Ki67 expression. Before surgical treatment, patients had no histories of radiotherapy or immunotherapy. Overall survival (OS) refers to the period from the initial biopsy confirming the diagnosis until death. CC staging was calculated according to the latest AJCC Cancer Staging Manual [13]. The research was approved by the hospital's human research ethics committee. Written informed consent was obtained from the patients for scientific research of their tissue samples.

\section{TMA and IHC staining}

All colon tissues samples (diameter $=1 \mathrm{~mm}$ ) were cut by core tissue biopsy from normal paraffin blocks which were made from resected tissues. Section location for samples were selected by a pathologist. Every TMA block included $7 \times 10$ different tissues. A total of 10 colon TMAs was processed by a Tissue Microarray System (Quick Ray, UT06, UNITMA, Korea). Cut sections from paraffin blocks $(4 \mu \mathrm{m})$ were placed on super frost-charged glass microscope slides. The slides were deparaffinized, rehydrated and incubated with $3 \% \mathrm{H}_{2} \mathrm{O}_{2}$ to block endogenous peroxidase activity. Then sections were incubated in polyclonal rabbit anti-human DSG2 IgG overnight at $4^{\circ} \mathrm{C}$ (dilution $1: 300 ; 13684-T 44$, Sino biological, China) and washed three times by phosphatebuffered saline (PBS). The reaction was performed by EnVision method (Dako, Carpinteria, CA, USA). Sections were incubated with 3,3'-diaminobenzidine chromogen solution for $10 \mathrm{~min}$, then counter stained with hematoxylin and covered by resin. PBS instead of DSG2 antibody was used as a negative control. The slices were evaluated by using Vectra 3.0 Automated Quantitative Pathology Imaging System (PerkinElmer, Connecticut, USA). The imaging system could automatically identify sample points. Staining intensity was defined as: 0 (no staining); $1+$ (weak staining); $2+$ (moderate staining); and $3+$ (intense staining). The last DSG2 expression score of every sample was calculated by the staining intensity multiplied by the percentage of cell staining. The minimum score could be 0 (no staining) and maximum score could be $300(3 \times 100 \%)$. The final scores were recorded for analysis.

\section{GBA analysis and gene set enrichment}

Guilt-by-association (GBA) analysis was used to investigate DSG2 function. Pearson's correlated proteincoded genes were analyzed for relationships with DSG2. Gene set enrichment analysis (GSEA v2.2.2 software http://www.broadinstitute.org/gsea) was used to identify the role of DSG2 in CC samples. The Kyoto Encyclopedia of Genes and Genomes (KEGG) was used for DSG2 pathway function annotation. The Bioconductor Cluster Profiler Package was used for KEGG functional enrichment analysis and was connected to GGplot2 for visualization. Protein-protein interaction (PPI) was constructed by Cytoscape_v3.7.0. 
The network of DSG2 and associated proteins was analyzed by STRING v10.5 (https: //string-db.org).

\section{Statistical analysis}

All statistical analyses were performed by SPSS 18.0 statistical software package (SPSS Inc. Chicago, IL). The scores from TMAs were divided into two parts by cutoff value using the X-tile software program (The Rimm Lab at Yale University; http://www.tissuearray.org/rimml ab) [14]. Two groups of data were tested by Student's $t$ test and $\chi^{2}$ test. Patient survival was calculated by the Kaplan-Meier method. Univariate and multivariate analyses used the Cox proportional hazards regression model. $P<0.05$ was regarded as significant.

\section{Results}

\section{DSG2 protein expression in CC by immunohistochemistry} staining

DSG2 protein expression was detected by IHC in CC tissues and related pericarcinomatous tissues and colitis tissues. DSG2 was expressed mainly on cells' membranes and partly in the cytoplasm. TMAs' scores were divided into groups with low or no expression and high expression using a cutoff value, 130 . The results showed that CC tissues had low DSG2 expression, compared with that pericarcinomatous tissues (Fig. 1). Low DSG2 protein expression was observed in 56.22\% (330/587) of CC samples, but only in $29.27 \%$ (12/41) colitis and $28.95 \%$ (33/114) of pericarcinomatous tissues (Table 1$)$.
Table 1 Dsg2 expression in colon tissues

\begin{tabular}{|c|c|c|c|c|c|}
\hline \multirow[t]{2}{*}{ Characteristics } & \multirow[t]{2}{*}{$\mathrm{n}$} & \multicolumn{2}{|c|}{ Dsg2 expression (\%) } & \multirow[t]{2}{*}{$\mathrm{X}^{2}$} & \multirow[t]{2}{*}{$\mathbf{P}$} \\
\hline & & Low or no & High & & \\
\hline Colitis & 41 & $12(29.27 \%)$ & $29(70.73 \%)$ & 36.26 & $<0.001$ \\
\hline Carcinoma & 587 & $330(56.22 \%)$ & $257(43.78 \%)$ & & \\
\hline $\begin{array}{l}\text { Pericarcinomatous } \\
\text { tissue }\end{array}$ & 114 & 33 (28.95\%) & 81 (71.05\%) & & \\
\hline
\end{tabular}

Dsg2 protein expression incolitis, carcinoma and pericarcinomatous tissue were detected by immunohistochemical staining

\section{Correlations of DSG2 protein expression and clinicopathological factors in CC}

The relationship between DSG2 expression level and CC patients' clinicopathological factors was analyzed, using IHC-stained TMA. DSG2 expression was significantly associated with differentiation $\left(\chi^{2}=8.77\right.$, $P=0.033)$, lymph node metastasis $\left(\chi^{2}=6.21, P=0.045\right)$, distant metastasis $\left(\chi^{2}=7.90, P=0.005\right)$ and AJCC stage $\left(X^{2}=18.54, P<0.001\right)$. However, DSG2 expression was not associated with the other factors, including age and Ki67 (Table 2).

\section{DSG2 protein expression was associated with poor prognosis in CC}

Univariate and multivariate analyses were used to evaluate the prognosis value of DSG2 expression and other clinical factors among $\mathrm{CC}$ patients. Univariate analysis showed that the CC patients' OS was associated with DSG2 expression $(\mathrm{HR}=0.996, P<0.001)$, tumor size $(\mathrm{HR}=1.295, \quad P<0.001)$, lymph node metastasis

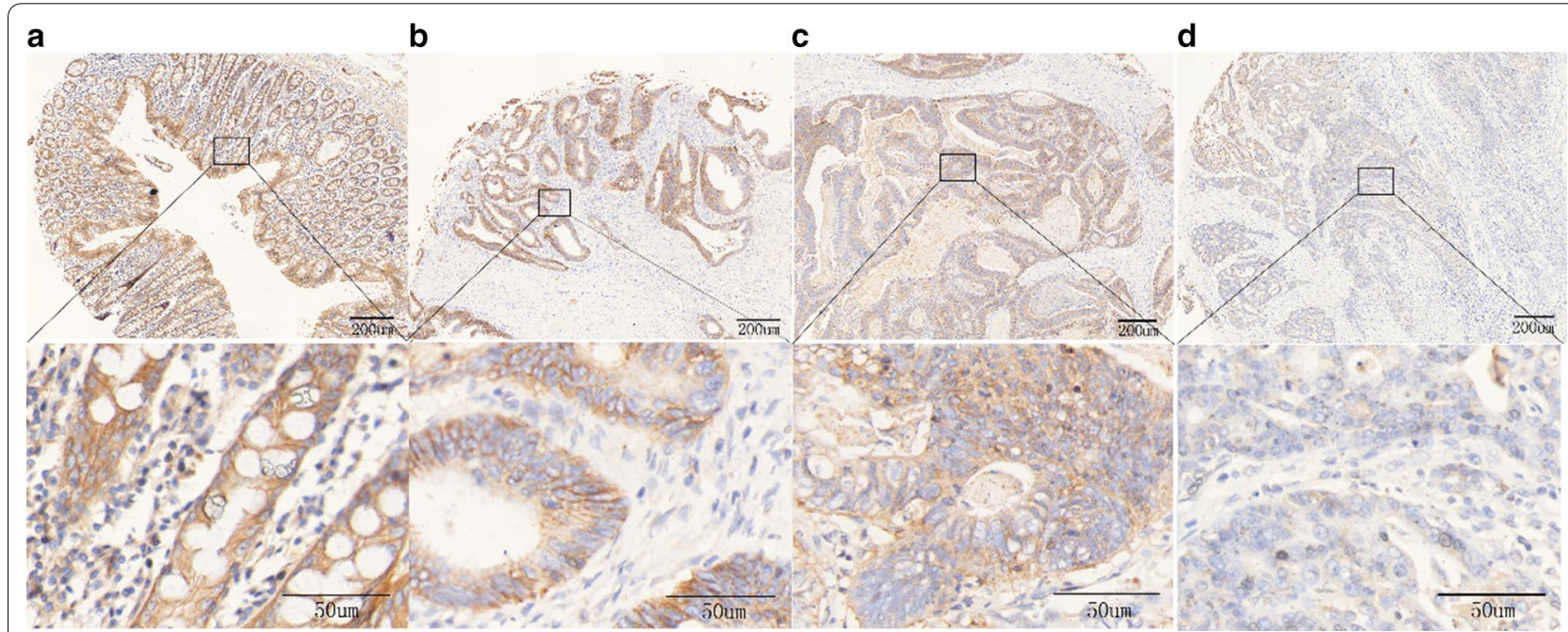

Fig. 1 DSG2 protein expression in colon tissues by immunohistochemistry staining. a Colitis tissue with high DSG2 expression, b high-level intraepithelial neoplasia of colon tissue with high DSG2 expression, c low-level intraepithelial neoplasia of colon tissue with low DSG2 expression, $\mathbf{d}$ adenocarcinoma with low DSG2 expression. Top row is the representative images of the DSG2 expression in colon tissues. Bottom row is the magnified images of the part area in the top row 
Table 2 Dsg2 expression level and CC patients' clinicopathological characteristics

\begin{tabular}{|c|c|c|c|c|c|}
\hline \multirow[t]{2}{*}{ Characteristics } & \multirow[t]{2}{*}{$\mathrm{n}$} & \multicolumn{2}{|l|}{ Dsg2 } & \multirow[t]{2}{*}{ Pearson $\mathrm{X}^{2}$} & \multirow[t]{2}{*}{ P-value } \\
\hline & & Low and no & High & & \\
\hline Total & 587 & $330(56.22 \%)$ & $257(43.78 \%)$ & & \\
\hline Gender & & & & 0.54 & 0.463 \\
\hline Male & 351 & 193 (54.99\%) & $158(45.01 \%)$ & & \\
\hline Female & 236 & 137 (58.05\%) & 99 (41.95\%) & & \\
\hline Age & & & & 0.79 & 0.376 \\
\hline$<60$ & 215 & $126(58.60 \%)$ & $89(41.40 \%)$ & & \\
\hline$\geq 60$ & 372 & 204 (54.84\%) & $168(45.16 \%)$ & & \\
\hline Location & & & & 3.02 & 0.389 \\
\hline Right & 188 & 110 (58.51\%) & 78 (41.49\%) & & \\
\hline Transverse & 77 & 46 (59.74\%) & $31(40.26 \%)$ & & \\
\hline Left & 114 & 67 (58.77\%) & 47 (41.23\%) & & \\
\hline Sigmoid & 208 & 107 (51.44\%) & $101(48.56 \%)$ & & \\
\hline Histological type & & & & 0.42 & 0.515 \\
\hline Adenocarcinoma & 522 & 291 (55.75\%) & $231(44.25 \%)$ & & \\
\hline Mucinous/SRCC & 65 & $39(60.00 \%)$ & $26(40.00 \%)$ & & \\
\hline Differentiation & & & & 8.77 & $0.033^{*}$ \\
\hline Well & 156 & 83 (53.21\%) & 73 (46.95\%) & & \\
\hline Moderate & 314 & $173(55.10 \%)$ & 141 (44.91\%) & & \\
\hline Poor & 99 & 58 (58.59\%) & 41 (41.41\%) & & \\
\hline Others $^{b}$ & 18 & 16 (88.89\%) & $2(11.11 \%)$ & & \\
\hline Tumor size & & & & 1.44 & 0.696 \\
\hline $\mathrm{T} 1$ & 42 & 25 (59.52\%) & $17(40.48 \%)$ & & \\
\hline $\mathrm{T} 2$ & 61 & 37 (60.66\%) & 24 (39.34\%) & & \\
\hline $\mathrm{T} 3$ & 200 & $115(57.50 \%)$ & 85 (42.50\%) & & \\
\hline $\mathrm{T} 4$ & 284 & $153(53.87 \%)$ & $131(46.13 \%)$ & & \\
\hline Lymph node metastasis & & & & 6.21 & $0.045^{*}$ \\
\hline No & 328 & $171(52.13 \%)$ & $157(47.87 \%)$ & & \\
\hline N1 & 168 & $99(58.93 \%)$ & $69(41.07 \%)$ & & \\
\hline N2 & 91 & $60(65.93 \%)$ & $31(34.07 \%)$ & & \\
\hline Distant metastasis & & & & 7.90 & $0.005^{*}$ \\
\hline MO & 495 & $266(53.74 \%)$ & $229(46.26 \%)$ & & \\
\hline M1 & 92 & $64(69.57 \%)$ & $28(30.43 \%)$ & & \\
\hline AJCC stage & & & & 18.54 & $<0.001^{*}$ \\
\hline 1 & 63 & $28(44.44 \%)$ & $35(55.56 \%)$ & & \\
\hline$\|$ & 199 & $95(47.74 \%)$ & $104(52.26 \%)$ & & \\
\hline III & 233 & $143(61.37 \%)$ & $90(38.63 \%)$ & & \\
\hline IV & 92 & $64(69.57 \%)$ & $28(30.43 \%)$ & & \\
\hline Venous invasion & & & & 0.15 & 0.697 \\
\hline Negative & 501 & $280(55.89 \%)$ & $221(44.11 \%)$ & & \\
\hline Positive & 86 & $50(58.14 \%)$ & $36(41.86 \%)$ & & \\
\hline Perineural invasion & & & & 0.24 & 0.623 \\
\hline Negative & 507 & $283(55.82 \%)$ & $224(44.18 \%)$ & & \\
\hline Positive & 80 & $47(58.75 \%)$ & $33(41.25 \%)$ & & \\
\hline Preoperative CEA, ng/ml & & & & 1.17 & 0.557 \\
\hline$\leq 5$ & 259 & $150(57.92 \%)$ & $109(42.08 \%)$ & & \\
\hline$>5$ & 285 & $154(54.04 \%)$ & $131(45.96 \%)$ & & \\
\hline Unknown & 43 & $26(60.47 \%)$ & $17(39.53 \%)$ & & \\
\hline Preoperative CA199, ng/ml & & & & 1.06 & 0.588 \\
\hline
\end{tabular}


Table 2 (continued)

\begin{tabular}{|c|c|c|c|c|c|}
\hline \multirow[t]{2}{*}{ Characteristics } & \multirow[t]{2}{*}{$n$} & \multicolumn{2}{|l|}{ Dsg2 } & \multirow[t]{2}{*}{ Pearson $X^{2}$} & \multirow[t]{2}{*}{ P-value } \\
\hline & & Low and no & High & & \\
\hline$\leq 37$ & 261 & 151 (57.85\%) & $110(42.15 \%)$ & & \\
\hline$>37$ & 281 & 152 (54.09\%) & $129(45.91 \%)$ & & \\
\hline Unknown & 45 & 27 (60.00\%) & 18 (40.00\%) & & \\
\hline Ki67 & & & & 0.58 & 0.444 \\
\hline Negative & 181 & 106 (58.56\%) & 75 (41.44\%) & & \\
\hline Positive & 406 & 224 (55.17\%) & 182 (44.83\%) & & \\
\hline
\end{tabular}

${ }^{*} P<0.05$ indicated a significant associated with clinical characteristics

a Mucinous carcinoma is 57 cases; SRCC (signet-ring cell carcinoma) is 8 cases

b No clear differentiation stage diagnosis

(HR $=0.642, P<0.001)$, distant metastasis $(\mathrm{HR}=3.098$, $P<0.001)$, AJCC stage $(\mathrm{HR}=1.331, P<0.001)$ and venous invasion $(\mathrm{HR}=2.735, P<0.001)$. When the above significant factors were processed by multivariate analysis, low DSG2 expression $(\mathrm{HR}=0.996, P<0.001)$, distant metastasis $(\mathrm{HR}=3.245, P<0.001)$, AJCC stage $(\mathrm{HR}=1.254$, $P=0.002)$ and venous invasion $(\mathrm{HR}=2.815, \mathrm{P}<0.001)$ were independent factors for OS (Table 3). KaplanMeier survival curves visually displayed the associations between TNM stage III + IV, low DSG2 expression, distant metastasis, and venous invasion, and CC patients' OS (Fig. 2).

\section{DSG2 expression in CC was tested by Gene set enrichment} analysis (GSEA) and Pearson correlation analysis

To ascertain DSG2's role in colon tumor formation and progression, an integrative analysis of CC microarray expression profiles was performed from GEO datasets. TCGA-colorectal cancer was used as basic dataset. The low DSG2 expression group was seen to be obviously enriched for protein sumoylation, P53 signaling pathway, ubiquitin-mediated proteolysis and protein dephosphorylation (Fig. 3a, Table 4). The protein network confirmed that KRAS and ADAM10 expression were associated with DSG2 (Fig. 3c). The protein network associated proteins in above four pathways were associated with DSG2 protein (Fig. 3b). Four different colors represented different proteins coded by genes that participated in the above four pathways. ADAM10 and KRAS were linked with DSG2 protein in the network.

\section{Discussion}

DSG2 was first found in colon tissues, and is also known as human desmoglein colon (HDGC) [15]. As a transmembrane protein, DSG2 is connect with desmocollin on the cell membrane and regulates cell adhesion. Desmoglein has four subtypes, of while DSG2 is the most widely expressed subtype in tissues [16]. Funakoshi et al. confirmed that desmosome junctions contribute to the maintenance of normal intestinal epithelial columnar morphology and antagonize epithelial-to-mesenchymal transition (EMT) which is a classical phenomenon for the metastasis of CC cells in humans $[17,18]$.

Our research indicated that DSG2 was low expression in CC, which are associated with CC's TNM stage, differentiation and AJCC stage. Kaplan-Meier analysis and the Cox proportion hazards model analysis showed that patients with low DSG2 expression have a poorer prognosis compared with high DSG2 expression.. Univariate and multivariate analyses suggested that DSG2 was an independent factor for CC patients' OS. All findings indicate that DSG2 could be a prognostic biomarker for CC.

Kundu et al. reported that reduction of desmosome proteins could decrease cell adhesion and promote metastasis in CC [19]. Vishnu C Ramani's study showed that DSG2 expression was reduced in pancreatic tumors, and it suggested that loss of desmosomal proteins play an important role in pancreatic cancer invasion [7]. Various classes of cell adhesion molecules, including desmosomes, are affected in cancers and their expression and function are regulated via various mechanisms [20]. The components that comprise intercellular junctions, such as desmosome play a critical role in cell adhesive function. The expression level of DSG2 which form the integral part of desmosomal adhesive core were also affected in tumors [21]. DSG2 was low expression in gastric cancer [22], squamous cell carcinoma [23], lung cancer [9] and prostate cancer [24]. Our results also indicated that low DSG2 expression was associated with CC TNM stage and patients' OS. According to the aforementioned studies, low expression of DSG2-the key protein in desmosome assemble-may induced tumor adhesion function disorder as well as tumor cell invasion and migration. Conversely, the research of Kamekura R et al. suggested that desmosome proteins can promote cell proliferation in CC [25]. The study showed that DSG2 
Table 3 Univariate and multivariable analysis of prognostic factors for overall survival in CC

\begin{tabular}{|c|c|c|c|c|c|c|}
\hline & \multicolumn{2}{|c|}{ Univariate analysis } & \multicolumn{2}{|c|}{ Multivariate analysis } & \multirow[t]{2}{*}{ P-value } & \multirow[t]{2}{*}{$95 \% \mathrm{Cl}$} \\
\hline & HR & P-value & $95 \% \mathrm{Cl}$ & HR & & \\
\hline \multicolumn{7}{|l|}{ Dsg2 expression } \\
\hline Low or no & Reference & & & & & \\
\hline High & 0.996 & $<0.001^{*}$ & $0.995-0.998$ & 0.996 & $<0.001^{*}$ & $0.995-0.998$ \\
\hline \multicolumn{7}{|l|}{ Age(year) } \\
\hline$\leq 60$ & Reference & & & & & \\
\hline$>60$ & 1.042 & 0.708 & $0.841-1.290$ & & & \\
\hline \multicolumn{7}{|l|}{ Gender } \\
\hline Male & Reference & & & & & \\
\hline Female & 1.119 & 0.102 & $0.992-1.149$ & & & \\
\hline \multicolumn{7}{|l|}{ Location } \\
\hline Right/Transverse & Reference & & & & & \\
\hline Left/Sigmoid & 1.004 & 0.919 & $0.922-1.094$ & & & \\
\hline \multicolumn{7}{|l|}{ Histological type } \\
\hline Adenocarcinoma & Reference & & & & & \\
\hline Mucinous/SRCC & 0.963 & 0.790 & $0.731-1.269$ & & & \\
\hline \multicolumn{7}{|l|}{ Differentiation } \\
\hline Well/Moderate & Reference & & & & & \\
\hline Poor/Others ${ }^{b}$ & 1.202 & 0.056 & $0.947-1.380$ & & & \\
\hline \multicolumn{7}{|l|}{ Tumor size } \\
\hline $\mathrm{T} 1 / \mathrm{T} 2$ & Reference & & & & & \\
\hline $\mathrm{T} 3 / \mathrm{T} 4$ & 1.295 & $<0.001^{*}$ & $1.144-1.465$ & 1.164 & 0.078 & $0.917-1.332$ \\
\hline \multicolumn{7}{|c|}{ Lymph node metastasis } \\
\hline No/N1 & Reference & & & & & \\
\hline $\mathrm{N} 2$ & 0.642 & $<0.001^{*}$ & $0.549-0.750$ & 0.931 & 0.081 & $0.846-1.633$ \\
\hline \multicolumn{7}{|l|}{ Distant metastasis } \\
\hline MO & Reference & & & & & \\
\hline M1 & 3.098 & $<0.001^{*}$ & $2.421-3.965$ & 3.245 & $<0.001^{*}$ & $2.462-4.276$ \\
\hline \multicolumn{7}{|l|}{ AJCC stage } \\
\hline$|/| \mid$ & Reference & & & & & \\
\hline III/IV & 1.331 & $<0.001^{*}$ & $1.186-1.495$ & 1.254 & $0.002^{*}$ & $1.09-1.442$ \\
\hline \multicolumn{7}{|l|}{ Venous invasion } \\
\hline Negative & Reference & & & & & \\
\hline Positive & 2.735 & $<0.001^{*}$ & $2.145-3.486$ & 2.815 & $<0.001^{*}$ & $2.175-3.644$ \\
\hline \multicolumn{7}{|l|}{ Perineural invasion } \\
\hline Negative & Reference & & & & & \\
\hline Positive & 1.481 & 0.075 & $0.951-1.730$ & & & \\
\hline \multicolumn{7}{|l|}{ CEA(ng/ml) } \\
\hline$\leq 5$ & Reference & & & & & \\
\hline$>5$ & 1.031 & 0.781 & $0.833-1.275$ & & & \\
\hline \multicolumn{7}{|l|}{ CA199(ng/ml) } \\
\hline$\leq 37$ & Reference & & & & & \\
\hline$>37$ & 0.950 & 0.634 & $0.768-1.175$ & & & \\
\hline \multicolumn{7}{|l|}{ Ki67 } \\
\hline Negative & Reference & & & & & \\
\hline Positive & 0.995 & 0.965 & $0.805-1.230$ & & & \\
\hline
\end{tabular}

Dsg2 expression, tumor size, lymph node metastasis, Distant metastasis, AJCC stage and venous invasion were included for multivariate analysis ${ }^{*} P<0.05$, statistically significant

a Mucinous carcinoma is 57 cases; SRCC (signet-ring cell carcinoma) is 8 cases

b No clear differentiation stage record

$H R$ hazard ratio, $\mathrm{Cl}$ confidence interval 

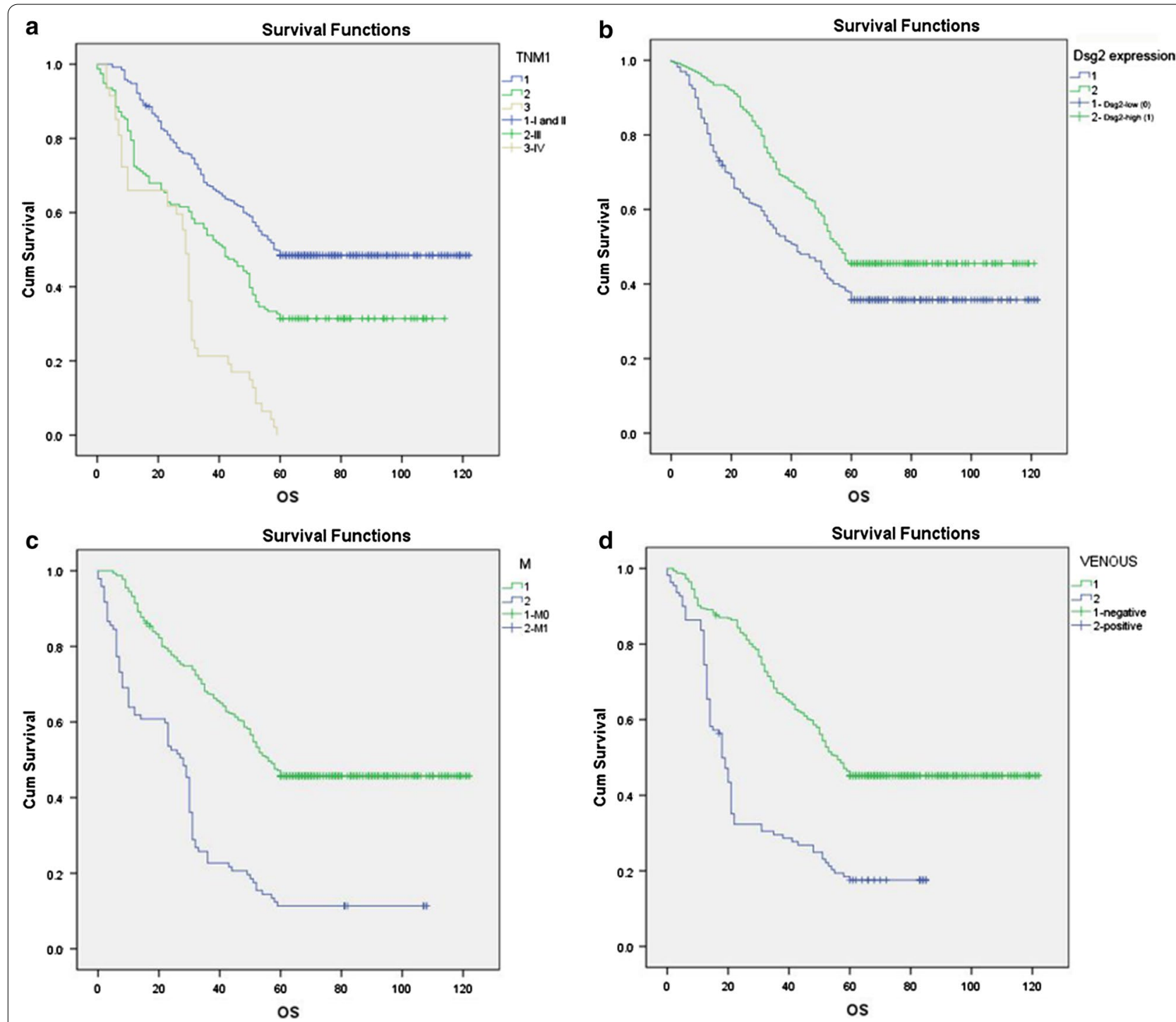

Fig. 2 Survival curve of CC patients by Kaplan-Meier plots and log-rank test. a The overall survival curve of patients with TNM (I and II) was significant higher than TNM(III and IV). b The overall survival curve of patients with DSG2 high expression was significantly higher than DSG2 low expression. c The overall survival curve of patients with distant metastasis was significantly lower than without distant metastasis. $\mathbf{d}$ The overall survival curve of patients with venous invasion was significantly lower than without venous invasion. All $P$ value in log-rank test is under 0.001

and DSC2 play opposite roles in tumor proliferation. Desmosome have a complex junction construction that is assembled by multiple proteins [26]. Altered expression of desmosome proteins may promote cancer development in certain contexts, but DSG2 affects carcinogenesis in different tumors in different ways, such as tumor composition, protein expression level, subcellular localization and tissue-specific proteins [27]. Further, these different findings may be due to the limitations of these carcinogenic alternative models. In physiological mouse models with intact immune systems in which cancers develop in the appropriate tissue microenvironment, the results indicate that the downregulation of desmosomes may contribute to malignant progression [28]. In our research, CC tissues collected from patients can better reflect the true condition of the tumor.

Our bioinformatics analysis indicated that P53 was associated with abnormally expressed DSG2 in CC. PMP-22 (PERK) is a tetraspan membrane protein that is transcriptionally activated by the P53 tumor suppressor [29]. And PERK is located to desmosomes in stratified epithelia and is crucial for proper desmosome assembly [30]. The link between those two proteins provides us more direction in DSG2 mechanism research. all three 
a

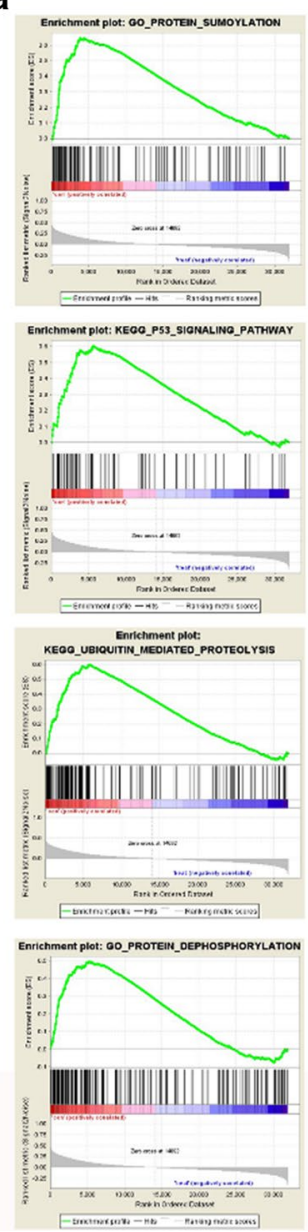

b
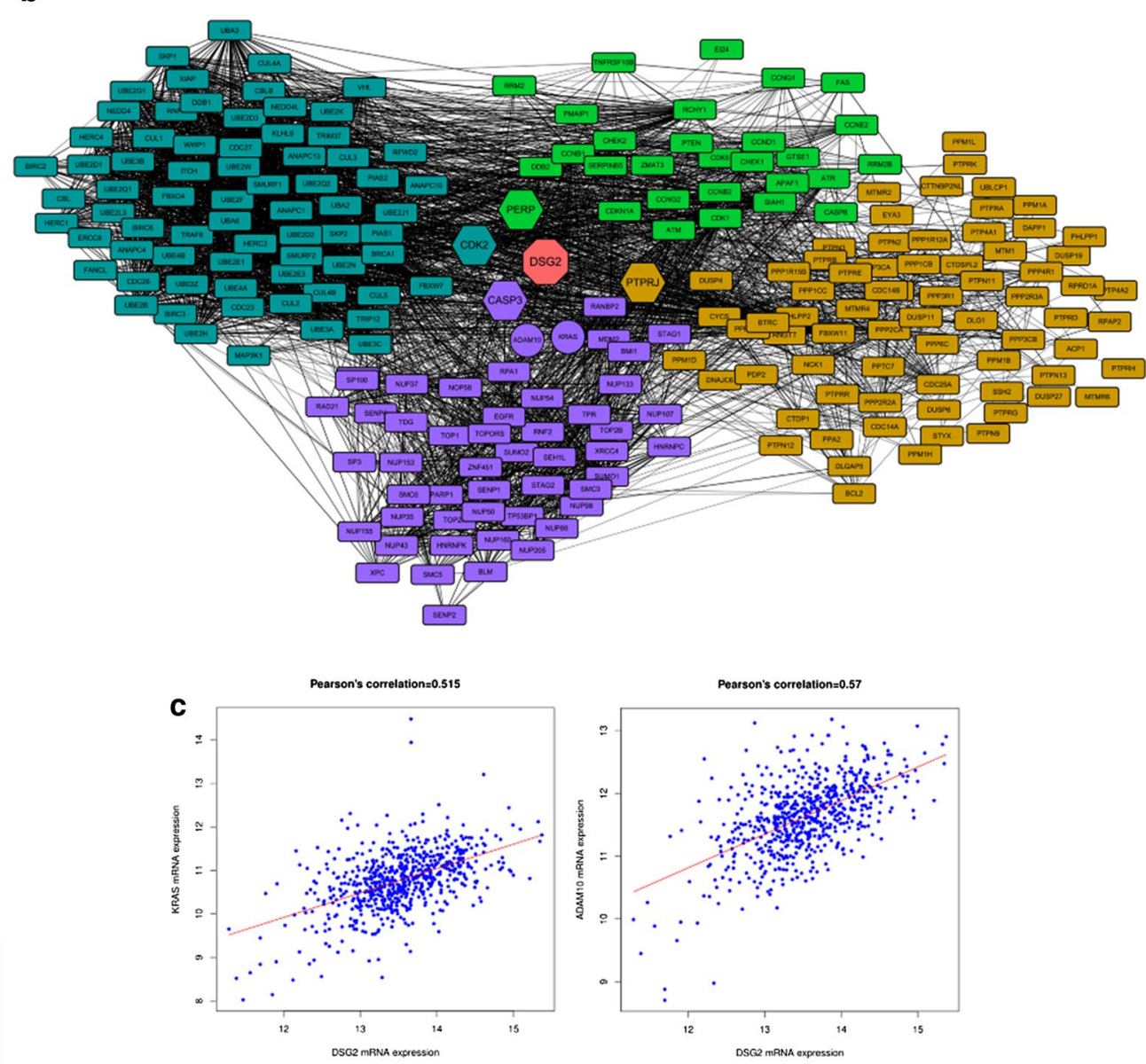

Fig. 3 The role of DSG2 in related signalling pathways? of colon cancer. a These four pathways were figured out be significant associated with DSG2 low expression. protein sumoylation; P53 signaling pathway; ubiquitin mediated proteolysis and protein dephosphorylation. b Proteinprotein interactions were extracted by STRINGV10.5 database and built in cytoscape_v3.7.0. proteins which were from same pathway were showed in same color. c KRAS and ADAM10 were positive correlated with DSG2 expression in colon cancer samples

Table 4 Four enriched pathways for differential expression Dsg2 in CC

\begin{tabular}{lllcrr}
\hline Pathway & ES & NES & FDR p-value & Normal p-value & FWER p-value \\
\hline Protein_sumoylation & 0.64 & 2.22 & 0.005 & $<0.001$ & 0.025 \\
P53_signaling_pathway & 0.61 & 2.15 & 0.003 & $<0.001$ & 0.003 \\
Ubiquitin_mediated_proteolysis & 0.60 & 2.26 & $<0.001$ & $<0.001$ & $<0.001$ \\
Protein_dephosphorylation & 0.50 & 2.17 & 0.008 & $<0.001$ & 0.052 \\
\hline
\end{tabular}

ES enrichment score, NES normal enrichment score, FDR false discovery rate, FWER family wise error rate

metabolic pathways (protein sumoylation, ubiquitinmediated proteolysis and protein dephosphorylation) have the close relationships with DSG2 expression in CC based on RNA expression level. From normal epithelial cells, mutated cells, into immortalized tumor cells, cellular metabolic activity gradually increases abnormally.
Upstream of the three metabolic pathways were biochemistry changes that affect cell mitosis and proliferation. Our bioinformatics network also showed that all four pathways were linked with DSG2 protein. These results suggest that DSG2 is related to tumor suppression and cancer-related protein activation. Pearson analysis 
said that ADAM10 and KRAS were positively linked with DSG2 at the mRNA level. The study of Klessner, et al. found that DSG2 shedding occurred in tumor cells, and ADAM10 shed N-cadherin and E-cadherin from the cell surface and reduced adhesion of neuronal and epithelial cells [31]. ADAM10 knock down resulted in greater accumulation of DSG2 fragments. ADAM10 was regulated by EGFR expression. When EGFR was blocked by PKI, ADAM10 could not be activated [32]. EGFR is a therapeutic target in several human tumors, including $\mathrm{CC}$, for which the anti-EGFR target antibody, panitumumab, is administered as monotherapy. KRAS encodes a small GTP-binding protein that acts as a self-inactivating signal transducer by cycling from GDP-bound states in response to stimulation by EGFR [33]. Mutant KRAS in many tumors is associated with lack of response to EGFR inhibitors. Therefore, DSG2 abnormal expression may participated in activating the EGFR-related pathway in CC malignant progression.

DSG2 was expressed mainly on cells' membranes and partly in the cytoplasm and was low expression in CC compared with pericarcinomatous tissues and colitis tissues. DSG2 was associated with some clinicopathological factors in CC including differentiation, lymph node metastasis, distant metastasis and AJCC stage. DSG2 was associated with poor prognosis in CC. DSG2 could be an independent prognostic biomarker for CC.

\section{Conclusions}

DSG2 is low expressed in CC compared with pericarcinomatous tissues and is an independent factor for $\mathrm{CC}$ patient's OS. Results indicated that DSG2 could be a prognostic biomarker for CC.

\section{Abbreviations \\ CC: colon cancer; DSG2: desmoglein2; OS: overall survival; AJCC: American Joint Commission on Cancer; TMAs: tissue microarrays; IHC: immunohisto- chemistry; PBS: phosphate-buffered saline; GSEA: gene set enrichment analy- sis; KEGG: Kyoto Encyclopedia of Genes and Genomes; PPI: protein-protein interaction; EMT: epithelial-to-mesenchymal transition.}

\section{Acknowledgements}

We thanks to the patient who provided the research sample and thank Liwen Bianji, Edanz Group China (www.liwenbianji.cn/ac), for editing the English text of a draft of this manuscript.

\section{Authors' contributions}

ZQF, and JZ designed the study; TTY, XG LZJ and GJJ acquired the data and drafted the article; WZ, LZJ, QT and TTY analyzed and interpreted the data; ZQF revised the article critically for important intellectual content. All authors read and approved the final manuscript.

\section{Funding}

This study was funded by NSFC (Natural Science Foundation of China) (Grant No.: 81773100). The funder provided financial support and ensured the authors' independence in designing the research, collecting, analyzing and interpreting the data and writing the manuscript.

\section{Availability of data and materials}

The datasets used and analyzed during the current study available from the corresponding author on reasonable request.

\section{Ethics approval and consent to participate}

This study was approved by the ethic committee of Nanjing Medical University and conducted in strict accordance with medical ethics standards (Nanjing Medical University Ethics Review (2017) No. 335). Written informed consent was obtained from study participants.

\section{Consent for publication}

Consent for publication was obtained from all authors.

\section{Competing interests}

The authors declare that they have no competing interests.

\section{Author details}

${ }^{1}$ Key Laboratory of Antibody Technique of National Health Commission, Nanjing Medical University, Nanjing 211166, China. ${ }^{2}$ Department of Pathology, Nanjing Medical University, Nanjing 211166, China. ${ }^{3}$ Department of Pathology, Nanjing First Hospital, Nanjing Medical University, Nanjing 210006, China. ${ }^{4}$ Huadong Medical Institute of Biotechniques, Nanjing 210000, China. 5 Jiangsu Key Lab. of Cancer Biomarkers, Prevention and Treatment, Collaborative Innovation Center for Cancer Personalized Medicine, Nanjing Medical University, Nanjing 211166, China.

Received: 17 April 2020 Accepted: 17 December 2020

Published online: 06 January 2021

\section{References}

1. Bray F, Ferlay J, Soerjomataram I, Siegel RL, Torre LA, Jemal A. Global cancer statistics 2018: GLOBOCAN estimates of incidence and mortality worldwide for 36 cancers in 185 countries. CA Cancer J Clin. 2018;68(6):394-424

2. Yang CS, Feng Q. Chemo/Dietary prevention of cancer: perspectives in China. J Biomed Res. 2014;28(6):447-55.

3. Siegel RL, Miller KD, Fedewa SA, Ahnen DJ, Meester R, Barzi A, Jemal A. Colorectal cancer statistics, 2017. CA Cancer J Clin. 2017;67(3):177-93.

4. Conde J, Oliva N, Zhang Y, Artzi N. Local triple-combination therapy results in tumour regression and prevents recurrence in a colon cancer model. Nat Mater. 2016;15(10):1128-38.

5. Nishihara R, Wu K, Lochhead P, Morikawa T, Liao X, Qian ZR, Inamura K, Kim SA, Kuchiba A, Yamauchi M, et al. Long-term colorectalcancer incidence and mortality after lower endoscopy. N Engl J Med. 2013;369(12):1095-105

6. Shaukat A, Mongin SJ, Geisser MS, Lederle FA, Bond JH, Mandel JS, Church TR. Long-term mortality after screening for colorectal cancer. N Engl J Med. 2013;369(12):1106-14.

7. Ramani VC, Hennings L, Haun RS. Desmoglein 2 is a substrate of kallikrein 7 in pancreatic cancer. BMC Cancer. 2008;8:373.

8. Barber AG, Castillo-Martin M, Bonal DM, Rybicki BA, Christiano AM, Cordon-Cardo C. Characterization of desmoglein expression in the normal prostatic gland. Desmoglein 2 is an independent prognostic factor for aggressive prostate cancer. PLoS ONE. 2014;9(6):e98786.

9. Saaber F, Chen Y, Cui T, Yang L, Mireskandari M, Petersen I. Expression of desmogleins 1-3 and their clinical impacts on human lung cancer. Pathol Res Pract. 2015;211(3):208-13.

10. Yashiro M, Nishioka N, Hirakawa K. Decreased expression of the adhesion molecule desmoglein-2 is associated with diffuse-type gastric carcinoma. Eur J Cancer. 2006;42(14):2397-403.

11. Liu Y, Chidgey M, Yang VW, Bialkowska AB. Krüppel-like factor 5 is essential for maintenance of barrier function in mouse colon. Am J Physiol Gastrointest Liver Physiol. 2017;313(5):G478-91.

12. Bye WA, Nguyen TM, Parker CE, Jairath V, East JE. Strategies for detecting colon cancer in patients with inflammatory bowel disease. Cochrane Database Syst Rev. 2017:9:D279.

13. Hari DM, Leung AM, Lee JH, Sim MS, Vuong B, Chiu CG, Bilchik AJ. AJCC Cancer Staging Manual 7th edition criteria for colon cancer: do the 
complex modifications improve prognostic assessment? J Am Coll Surg 2013;217(2):181-90.

14. Lin JC, Wu YY, Wu JY, Lin TC, Wu CT, Chang YL, Jou YS, Hong TM, Yang PC TROP2 is epigenetically inactivated and modulates IGF-1R signalling in lung adenocarcinoma. EMBO Mol Med. 2012;4(6):472-85.

15. Arnemann J, Spurr NK, Magee Al, Buxton RS. The human gene (DSG2) coding for HDGC, a second member of the desmoglein subfamily of the desmosomal cadherins, is, like DSG1 coding for desmoglein DGI, assigned to chromosome 18. Genomics. 1992:13(2):484-6.

16. Berika M, Garrod D. Desmosomal adhesion in vivo. Cell Commun Adhes 2014;21(1):65-75

17. Funakoshi S, Ezaki T, Kong J, Guo RJ, Lynch JP. Repression of the desmocollin 2 gene expression in human colon cancer cells is relieved by the homeodomain transcription factors $\mathrm{Cd} \times 1$ and $\mathrm{Cd} \times 2$. Mol Cancer Res. 2008;6(9):1478-90.

18. Sulaiman A, Yao ZM, Wang LS. Re-evaluating the role of epithelial-mesenchymal-transition in cancer progression. J Biomed Res. 2018;32(2):81-90.

19. Kundu ST, Gosavi P, Khapare N, Patel R, Hosing AS, Maru GB, Ingle A, Decaprio JA, Dalal SN. Plakophilin3 downregulation leads to a decrease in cell adhesion and promotes metastasis. Int J Cancer. 2008;123(10):2303-14.

20. Klessner JL, Desai BV, Amargo EV, Getsios S, Green KJ. EGFR and ADAMs cooperate to regulate shedding and endocytic trafficking of the desmosomal cadherin desmoglein 2. Mol Biol Cell. 2009:20(1):328-37.

21. van Roy F. Beyond E-cadherin: roles of other cadherin superfamily members in cancer. Nat Rev Cancer. 2014;14(2):121-34.

22. Biedermann K, Vogelsang H, Becker I, Plaschke S, Siewert JR, Hofler H, Keller $\mathrm{G}$. Desmoglein 2 is expressed abnormally rather than mutated in familial and sporadic gastric cancer. J Pathol. 2005;207(2):199-206.

23. Overmiller AM, Pierluissi JA, Wermuth PJ, Sauma S, Martinez-Outschoorn U, Tuluc M, Luginbuhl A, Curry J, Harshyne LA, Wahl JK, et al. Desmoglein 2 modulates extracellular vesicle release from squamous cell carcinoma keratinocytes. FASEB J. 2017;31(8):3412-24.

24. Hütz K, Zeiler J, Sachs L, Ormanns S, Spindler V. Loss of desmoglein 2 promotes tumorigenic behavior in pancreatic cancer cells. Mol Carcinogen. 2017;56(8):1884-95.
25. Kamekura R, Kolegraff KN, Nava P, Hilgarth RS, Feng M, Parkos CA, Nusrat A. Loss of the desmosomal cadherin desmoglein-2 suppresses colon cancer cell proliferation through EGFR signaling. Oncogene. 2014;33(36):4531-6.

26. Lowndes M, Rakshit S, Shafraz O, Borghi N, Harmon RM, Green KJ, Sivasankar S, Nelson WJ. Different roles of cadherins in the assembly and structural integrity of the desmosome complex. J Cell Sci. 2014;127(Pt 10):2339-50.

27. Dusek RL, Attardi LD. Desmosomes: new perpetrators in tumour suppression. Nat Rev Cancer. 2011;11(5):317-23.

28. Chun MG, Hanahan D. Genetic deletion of the desmosomal component desmoplakin promotes tumor microinvasion in a mouse model of pancreatic neuroendocrine carcinogenesis. PLoS Genet. 2010;6(9):e1001120.

29. Awais R, Spiller DG, White MR, Paraoan L. p63 is required beside p53 for PERP-mediated apoptosis in uveal melanoma. Br J Cancer. 2016;115(8):983-92

30. Ihrie RA, Marques MR, Nguyen BT, Horner JS, Papazoglu C, Bronson RT, Mills AA, Attardi LD. Perp is a p63-regulated gene essential for epithelial integrity. Cell. 2005;120(6):843-56.

31. Amado RG, Wolf M, Peeters M, Van Cutsem E, Siena S, Freeman DJ, Juan T, Sikorski R, Suggs S, Radinsky R, et al. Wild-type KRAS is required for panitumumab efficacy in patients with metastatic colorectal cancer. J Clin Oncol. 2008;26(10):1626-34.

32. Maretzky T, Reiss K, Ludwig A, Buchholz J, Scholz F, Proksch E, de Strooper B, Hartmann D, Saftig P. ADAM10 mediates E-cadherin shedding and regulates epithelial cell-cell adhesion, migration, and beta-catenin translocation. Proc Natl Acad Sci USA. 2005;102(26):9182-7.

33. Kam CY, Dubash AD, Magistrati E, Polo S, Satchell K, Sheikh F, Lampe PD, Green KJ: Desmoplakin maintains gap junctions by inhibiting Ras/MAPK and lysosomal degradation of connexin-43. J Cell Biol; 2018.

\section{Publisher's Note}

Springer Nature remains neutral with regard to jurisdictional claims in published maps and institutional affiliations.
Ready to submit your research? Choose BMC and benefit from:

- fast, convenient online submission

- thorough peer review by experienced researchers in your field

- rapid publication on acceptance

- support for research data, including large and complex data types

- gold Open Access which fosters wider collaboration and increased citations

- maximum visibility for your research: over $100 \mathrm{M}$ website views per year

At BMC, research is always in progress.

Learn more biomedcentral.com/submissions 